\title{
A Clinical Perspective of Anti-Fibrotic Therapies for Cardiovascular Disease
}

\author{
Lu Fang ${ }^{1 *}$, Andrew J. Murphy ${ }^{1}$ and Anthony M. Dart ${ }^{1,2}$ \\ ${ }^{1}$ Baker IDI Heart and Diabetes Institute, Melbourne, VIC, Australia, ${ }^{2}$ Department of Cardiovascular Medicine, The Alfred \\ Hospital, Melbourne, VIC, Australia
}

\section{OPEN ACCESS}

Edited by:

Chrishan S. Samuel,

Monash University, Australia

Reviewed by:

Daniele Bani,

University of Florence, Italy

Thomas Bernd Dschietzig,

Immundiagnostik AG, Germany

*Correspondence:

Lu Fang

karenlu.fang@bakeridi.edu.au

Specialty section:

This article was submitted to Cardiovascular and Smooth Muscle

Pharmacology,

a section of the journal

Frontiers in Pharmacology

Received: 24 February 2017

Accepted: 22 March 2017

Published: 06 April 2017

Citation:

Fang L, Murphy AJ and Dart AM (2017) A Clinical Perspective of

Anti-Fibrotic Therapies for Cardiovascular Disease.

Front. Pharmacol. 8:186.

doi: 10.3389/fphar.2017.00186
Cardiac fibrosis are central to various cardiovascular diseases. Research on the mechanisms and therapeutic targets for cardiac fibrosis has advanced greatly in recent years. However, while many anti-fibrotic treatments have been studied in animal models and seem promising, translation of experimental findings into human patients has been rather limited. Thus, several potential new treatments which have shown to reduce cardiac fibrosis in animal models have either not been tested in humans or proved to be disappointing in clinical trials. A majority of clinical studies are of small size or have not been maintained for long enough periods. In addition, although some conventional therapies, such as renin-angiotensin-aldosterone system (RAAS) inhibitors, have been shown to reduce cardiac fibrosis in humans, cardiac fibrosis persists in patients with heart failure even when treated with these conventional therapies, indicating a need to develop novel and effective anti-fibrotic therapies in cardiovascular disease. In this review article, we summarize anti-fibrotic therapies for cardiovascular disease in humans, discuss the limitations of currently used therapies, along with possible reasons for the failure of so many anti-fibrotic drugs at the clinical level. We will then explore the future directions of anti-fibrotic therapies on cardiovascular disease, and this will include emerging anti-fibrotics that show promise, such as relaxin. A better understanding of the differences between animal models and human pathology, and improved insight into carefully designed trials on appropriate end-points and appropriate dosing need to be considered to identify more effective anti-fibrotics for treating cardiovascular fibrosis in human patients.

Keywords: cardiac fibrosis, anti-fibrotic therapies, clinical trials, diffuse fibrosis, cardiac magnetic resonance imaging, collagen turnover markers, diastolic function

\section{INTRODUCTION}

Cardiac fibrosis is a hallmark of various cardiovascular disease such as hypertension, myocardial infarction (MI), and ischemic, dilated, and hypertrophic cardiomyopathies. Cardiac fibrosis not only leads to cardiac diastolic dysfunction, but is also a major determinant of malignant arrhythmias and end-stage systolic heart failure and consequently, increases the risk of cardiac death. There are two types of fibrosis: regional fibrosis (reparative fibrosis, scarring from MI) and diffuse fibrosis (reactive fibrosis, interstitial fibrosis in response to different stimuli). Cardiac fibrosis can be definitively diagnosed by endomyocardial biopsies, but they are an invasive evaluation only representative in diffuse fibrosis. Circulating biomarkers, particularly collagen turnover markers, are widely used to noninvasively assess cardiac fibrosis, however they are not reliable and unable to differentiate regional fibrosis from diffuse fibrosis. Cardiac magnetic 
resonance imaging $(\mathrm{CMR})$ is an emerging technique to accurately and noninvasively evaluate regional and diffuse cardiac fibrosis by late gadolinium enhancement and post-contrast myocardial longitudinal relaxation time (T1) mapping, respectively, but CMR is expensive and not easily accessible. Functional consequences of cardiac fibrosis, particularly impaired left ventricular (LV) relaxation and heart failure, are also potential, albeit nonspecific, markers of fibrosis.

It is known that a complex interaction involving a network of growth factors/cytokines/hormones and fibroblasts and other cell types (such as cardiomyocytes, monocytes, lymphocytes) is responsible for initiating and maintaining fibrotic response (Kong et al., 2014). In addition to resident fibroblasts, fibroblasts originate from circulating pecursors, sometimes termed fibrocytes (Fang et al., 2013), endothelial cells or epithelial cells (Kong et al., 2014). Renin-angiotensin-aldosterone system (RAAS), growth factors [such as transforming growth factor (TGF)- $\beta$ ], endothelin, matricellular proteins (such as connective tissue growth factor (CTGF) and proinflammatory factors (such as tumor necrosis factor (TNF- $\alpha$ ), interleukin (IL)-6 and IL-1) are some of the best studied mediators implicated in cardiac fibrosis (Kong et al., 2014). Recently, new mediators with therapeutic potential of cardiac fibrosis have been emerging such as cardiotrophin-1, galectin, and miRNAs etc. (Fang et al., 2015; Heymans et al., 2015). Although many anti-fibrotic therapies on cardiac fibrosis seem promising in experimental models, clinical data are limited and mixed. Most of new anti-fibrotic therapies have not been evaluated in patients. Some clinical data have demonstrated benefits on cardiac fibrosis mainly with RAAS inhibitors, but most clinical trials on anti-fibrotic drugs are disappointing. This review will summarize findings from clinical trials of anti-fibrotic therapies on cardiac fibrosis (Table 1) and discuss the discrepancy between animal research and clinical trials as well as future directions.

\section{ANTI-FIBROTIC THERAPIES ON CARDIAC FIBROSIS IN CLINICAL TRIALS}

\section{RAAS Inhibitors}

The first family of anti-fibrotic drugs are inhibitors of angiotensin II. Angiotensin II interacts with angiotensin II type I receptors, which stimulates fibroblast proliferation, and increases collagen synthesis (Kong et al., 2014). Several clinical studies have shown that both angiotensin-converting enzyme (ACE) inhibitors and angiotensin receptor blockers reduce cardiac fibrosis in patients independent of their antihypertensive effects. In hypertensive patients, endomyocardial biopsies at baseline and 6 months revealed a decrease of collagen volume fraction (CVF) only in the group treated with lisinopril $(n=18)$, but not with hydrochlorothiazide $(n=17)$ (Brilla et al., 2000). A comparison between losartan $(n=21)$ and amlodipine $(n=16)$ given for 1 year in hypertensive patients revealed that only losartan significant decreased both CVF (by endomyocardial biopsies) and the carboxy-terminal peptide of procollagen type I (PICP) (López et al., 2001). Another study demonstrated that in patients with hypertensive heart disease, losartan treatment for 12 months decreased CVF (by endomyocardial biopsies) and LV chamber stiffness in patients with severe fibrosis $(n=7)$, but not in those with nonsevere fibrosis $(n=12)$ (Díez et al., 2002). In patients with end-stage renal disease, losartan $(n=13)$ more effectively suppressed cardiac fibrosis than did enalapril ( $n=13)$ or amlodipine $(n=13)$ (Shibasaki et al., 2005). Another small study showed attenuation of progression of cardiac fibrosis with losartan in patients with nonobstructive hypertrophic cardiomyopathy (Shimada et al., 2013). Treatment with candesartan for 24 months also reduced the amino-terminal peptide of type III procollagen (PIIINP) in patients with atrial fibrillation (Kawamura et al., 2010).

The mineralo-corticoid receptor antagonists, spironolactone and eplerenone, also have anti-fibrotic effects in humans. Additional treatment of spironolactone for 6 months improved LV diastolic function and decreased PICP and PIIINP in 80 patients with metabolic syndrome treated with angiotensin II inhibition (Kosmala et al., 2011). In another study of 113 patients with obesity and mild LV diastolic dysfunction, spironolactone treatment for 6 months improved myocardial deformation and decreased PICP and PIIINP (Kosmala et al., 2013). In 44 patients with diastolic heart failure, eplerenone reduced PIIINP at 12 months after treatment, associated with modest improvement of diastolic function (Mak et al., 2009). Similar findings were made in another study showing that eplerenone reduced the amino-terminal peptide of type I procollagen (PINP) and PICP in 44 patients with heart failure with preserved ejection fraction (Deswal et al., 2011).

Although the above clinical studies have shown that RAAS inhibitors reduces cardiac fibrosis in humans, the study population in these studies is rather small. Furthermore, inhibition of RAAS only modestly regresses cardiac fibrosis. Cardiac fibrosis persists in heart failure patients even when treated as recommended by the official guidelines (Querejeta et al., 2004). Thus, there is a compelling need to develop novel and effective anti-fibrotic therapies in cardiovascular disease.

\section{Inflammation Modulators}

Inflammatory modulation might have beneficial effects on cardiac fibrosis and heart failure since inflammation is involved in the formation and progression of cardiac fibrosis. TNF- $\alpha$ plays an important role in cardiac fibrosis. However, the RENEWAL study (Mann et al., 2004) which examined the effect of TNF- $\alpha$ antagonist etanercept in patients with heart failure was negative. Additionally, the ATTACH trial was stopped prematurely as the high dose of the TNF- $\alpha$ antagonist infliximab increased allcause mortality in patients with moderate-to-severe chronic heart failure (Chung et al., 2003). The finding that TNF receptor 1 and 2 exert opposing effects on cardiac remodeling may partly explain that direct blockade of one inflammatory actor could cause these unexpected clinical results (Hamid et al., 2009).

Statins possess potent anti-inflammatory effects and are widely used in cardiovascular disease. Rosuvastatin attenuated cardiac fibrosis in animal models (Chang et al., 2009), which is supported by a small clinical study showing that statin therapy for 6 months reduced PIIINP in heart failure population $(n=56)$ (Abulhul et al., 2012). However, two large-scale clinical 
TABLE 1 | Anti-fibrotic therapies on cardiac fibrosis in clinical trials.

\begin{tabular}{|c|c|c|c|c|}
\hline Study & Agent & $\begin{array}{l}\text { Length of } \\
\text { treatment }\end{array}$ & $\begin{array}{c}\text { Patient } \\
\text { included }(n)\end{array}$ & Main findings \\
\hline \multicolumn{5}{|l|}{ RAAS INHIBITORS } \\
\hline Brilla et al., 2000 & Lisinopril & 6 months & 35 & Lisinopril but not hydrochlorothiazide decreased CVF in hypertensive patients. \\
\hline López et al., 2001 & Losartan & 12 months & 37 & Losartan but not amlodipine decreased CVF and PICP in hypertensive patients. \\
\hline Díez et al., 2002 & Losartan & 12 months & 19 & $\begin{array}{l}\text { Losartan decreased CVF and LV chamber stiffness in hypertensive patients with } \\
\text { severe fibrosis, but not in those with nonsevere fibrosis. }\end{array}$ \\
\hline Shibasaki et al., 2005 & Losartan & 6 months & 39 & $\begin{array}{l}\text { Losartan more effectively suppressed cardiac fibrosis than enalapril or } \\
\text { amlodipine in patients with end-stage renal disease. }\end{array}$ \\
\hline Shimada et al., 2013 & Losartan & 12 months & 20 & $\begin{array}{l}\text { Losartan attenuated the progression of cardiac fibrosis in patients with } \\
\text { nonobstructive hypertrophic cardiomyopathy. }\end{array}$ \\
\hline Kawamura et al., 2010 & Candesartan & 24 months & 153 & Candesartan reduced PIIINP in patients with atrial fibrillation. \\
\hline Kosmala et al., 2011 & Spironolactone & 6 months & 80 & $\begin{array}{l}\text { Additional spironolactone decreased PICP and PIIINP in patients with metabolic } \\
\text { syndrome. }\end{array}$ \\
\hline Kosmala et al., 2013 & Spironolactone & 6 months & 113 & $\begin{array}{l}\text { Spironolactone improved myocardial deformation and decreased PICP and } \\
\text { PIIINP in patients with obesity and mild LV diastolic dysfunction. }\end{array}$ \\
\hline Mak et al., 2009 & Eplerenone & 12 months & 44 & $\begin{array}{l}\text { Eplerenone reduced PIIINP and modestly improved diastolic function in patients } \\
\text { with diastolic heart failure. }\end{array}$ \\
\hline Deswal et al., 2011 & Eplerenone & 6 months & 44 & $\begin{array}{l}\text { Eplerenone reduced PINP and PICP in patients with heart failure with preserved } \\
\text { ejection fraction. }\end{array}$ \\
\hline \multicolumn{5}{|c|}{ INFLAMMATION MODULATORS } \\
\hline RENEWAL & Etanercept & 24 weeks & 2,048 & $\begin{array}{l}\text { The study ruled out a clinically relevant benefit of etanercept on the rate of death } \\
\text { or hospitalization due to chronic heart failure in patients with heart failure. }\end{array}$ \\
\hline ATTACH & Infliximab & $\begin{array}{l}\text { At } 0,2,6 \\
\text { weeks }\end{array}$ & 150 & $\begin{array}{l}\text { High dose of infliximab increased all-cause mortality in patients with } \\
\text { moderate-severe heart failure. }\end{array}$ \\
\hline Abulhul et al., 2012 & Atorvastatin & 6 months & 56 & Atorvastatin reduced PIIINP in heart failure patients. \\
\hline CORONA & Rosuvastatin & 32.8 months & 5,011 & $\begin{array}{l}\text { Rosuvastatin did not reduce the primary outcome or the number of deaths from } \\
\text { any cause in older patients with systolic heart failure. }\end{array}$ \\
\hline GISSIF-HF & Rosuvastatin & 3.9 years & 4,574 & $\begin{array}{l}\text { Rosuvastatin daily did not affect clinical outcomes in patients with chronic heart } \\
\text { failure of any cause. }\end{array}$ \\
\hline UNIVERSAL & Rosuvastatin & 6 months & 86 & $\begin{array}{l}\text { Rosuvastatin did not beneficially alter parameters of LV remodeling in patients } \\
\text { with chronic systolic heart failure. }\end{array}$ \\
\hline \multicolumn{5}{|l|}{ TGF- $\beta$ INHIBITORS } \\
\hline PRESTO & Tranilast & $\begin{array}{l}1, \text { or } 3 \\
\text { months }\end{array}$ & 11,484 & $\begin{array}{l}\text { Tranilast did not improve the quantitative measures of restenosis (angiographic } \\
\text { and intravascular ultrasound) or its clinical sequelae in patients receiving } \\
\text { successful percutaneous coronary intervention. }\end{array}$ \\
\hline \multicolumn{5}{|c|}{ ENDOTHELIN INHIBITORS } \\
\hline Sütsch et al., 1998 & Bosentan & 2 weeks & 36 & $\begin{array}{l}\text { Bosentan improved systemic and pulmonary hemodynamics in heart failure } \\
\text { patients who were symptomatic with standard triple-drug therapy. }\end{array}$ \\
\hline EARTH & Darusentan & 24 weeks & 642 & $\begin{array}{l}\text { Darusentan did not improve cardiac remodeling or clinical outcomes in patients } \\
\text { with chronic heart failure. }\end{array}$ \\
\hline Prasad et al., 2006 & Enrasentan & 6 months & 72 & $\begin{array}{l}\text { In asymptomatic patients with LV dysfunction, LVEDVI increased over } 6 \text { months } \\
\text { with enrasentan compared with enalapril treatment. }\end{array}$ \\
\hline \multicolumn{5}{|c|}{ SELECTIVE HEART RATE-REDUCING DRUG } \\
\hline SHIFT & Ivabradine & $\begin{array}{l}22.9 \text { month } \\
\text { follow up }\end{array}$ & 6,558 & Ivabradine improved clinical outcomes in patients with symptomatic heart failure. \\
\hline SHIFT substudy & Ivabradine & $\begin{array}{l}8 \text { month } \\
\text { follow up }\end{array}$ & 411 & Ivabradine reversed cardiac remodeling in patients with heart failure. \\
\hline \multicolumn{5}{|l|}{ LOOP DIURETICS } \\
\hline López et al., 2004 & Torsemide & 8 months & 36 & $\begin{array}{l}\text { Torsemide but not furosemide reduced PICP and CVF in hypertensive patients } \\
\text { with symptomatic heart failure. }\end{array}$ \\
\hline López et al., 2007 & Torsemide & 8 months & 22 & $\begin{array}{l}\text { Torsemide but not furosemide decreased PCP in patients with chronic heart } \\
\text { failure. }\end{array}$ \\
\hline López et al., 2009 & Torsemide & 8 months & 24 & $\begin{array}{l}\text { Torsemide corrected both lysyl oxidase overexpression and enhanced collagen } \\
\text { cross-linking leading to normalization of LV chamber stiffness in patients with } \\
\text { heart failure. }\end{array}$ \\
\hline
\end{tabular}

(Continued) 


\section{TABLE 1 | Continued}

\begin{tabular}{|c|c|c|c|c|}
\hline Study & Agent & $\begin{array}{l}\text { Length of } \\
\text { treatment }\end{array}$ & $\begin{array}{l}\text { Patient } \\
\text { included }(n)\end{array}$ & Main findings \\
\hline TORAFIC & Torsemide & 8 months & 155 & $\begin{array}{l}\text { In hypertensive patients with chronic heart failure randomized to torsemide or } \\
\text { furosemide, there were no difference in PICP levels between the two groups. }\end{array}$ \\
\hline \multicolumn{5}{|c|}{ CYCLIC GMP-SPECIFIC PHOSPHODIESTERASE TYPE-5A INHIBITOR } \\
\hline Giannetta et al., 2012 & Sildenafil & 3 months & 59 & $\begin{array}{l}\text { Sildenafil improved LV contraction parameters and reduced TGF- } \beta \text { and MCP- } 1 \text { in } \\
\text { patients with diabetic cardiomyopathy. }\end{array}$ \\
\hline Redfield et al., 2013 & Sildenafil & 24 weeks & 216 & $\begin{array}{l}\text { Sildenafil did not improve exercise activity in patients with heart failure with } \\
\text { preserved ejection fraction. }\end{array}$ \\
\hline \multicolumn{5}{|c|}{ MATRIX METALLOPROTEINASE INHIBITOR } \\
\hline PREMIER & PG-116800 & 90 days & 253 & $\begin{array}{l}\text { PG-11680 did not prevent LV remodeling or improve clinical outcomes } 90 \text { days } \\
\text { after myocardial infarction. }\end{array}$ \\
\hline \multicolumn{5}{|l|}{ RELAXIN } \\
\hline Pre-RELAX-AHF & Relaxin & $48 \mathrm{~h}$ & 234 & $\begin{array}{l}\text { Relaxin improved dyspnoea and lowered cardiovascular deaths or readmissions } \\
\text { due to heart or renal failure at day } 60 \text { in patients with acute heart failure. }\end{array}$ \\
\hline RELAX-AHF & Serelaxin & $48 \mathrm{~h}$ & 1,161 & $\begin{array}{l}\text { Serelaxin improved dyspnoea and reduced cardiovascular deaths and all-cause } \\
\text { mortality through day } 180 \text { in patients with acute heart failure. }\end{array}$ \\
\hline
\end{tabular}

CVF, collagen volume fraction; PICP, the carboxy-terminal peptide of procollagen type I; LV, left ventricular; PIIINP, the amino-terminal peptide of type III procollagen; PINP, the aminoterminal peptide of type I procollagen (PINP); PCP, procollagen type I carboxy-terminal proteinase; TGF- $\beta$, transforming growth factor- $\beta$; MCP-1, monocyte chemoattractant protein-1; LVEDVI, LV end diastolic volume index.

trials, the CORONA(Kjekshus et al., 2007) and GISSIF-HF (Tavazzi et al., 2008) observed a neutral effect of rosuvastatin compared to placebo on major clinical outcomes in heart failure. Beneficial effects of statin on cardiac remodeling were not observed in universal trial either (Krum et al., 2007). A substudy of universal trial actually showed reduced coenzyme-10 and increased serum collagen markers in the statin-treated group (Ashton et al., 2011). So, statin's effect on cardiac fibrosis in human are generally disappointing. Peroxisome proliferatoractivated receptor (PPAR) agonists have anti-inflammation properties. Preclinical data showed that PPAR- $\alpha$ agonist inhibited cardiac fibrosis and improved cardiac function (Ogata et al., 2004). However, considerable controversy exists on the cardiac safety profile of PPAR agonists (Sarma, 2012). Overall, there is lack of effective inflammatory modulators to inhibit cardiac fibrosis in patients. However, the negative results of inflammatory modulators do not necessarily mean the end of inflammatory modulators in cardiac fibrosis. Future studies should identify the crucial actors and their mechanisms of action in the immunopathogenesis of cardiac fibrosis, which is a prerequisite for the development of new inflammatory modulators in patients with cardiac fibrosis. Selective p38 MAPK inhibitors blocking the secretion of TNF- $\alpha$ and decreasing cardiac fibrosis in mice (Westermann et al., 2006) may be a new treatment modality in humans.

\section{TGF- $\beta$ inhibitors}

TGF- $\beta$ plays a central role in activating cardiac fibrosis and it activates both canonical (ALK/Smad2/3/Smad4) and noncanonical (TAK/p-38/JNK and NOX4/ROS) signaling pathways. Anti-TGF- $\beta$ antibodies and ALK5 inhibitors attenuated cardiac fibrosis in animal models, but they were associated with adverse cardiovascular effects (Frantz et al., 2008; Engebretsen et al., 2014), suggesting that targeting canonical TGF- $\beta$ signaling pathway might not be applicable clinically. While TGF- $\beta$ promotes fibrogenesis, it also inhibits inflammation, suggesting that broad targeting of TGF- $\beta$ may be problematic. Alternatively, targeting TAK or NOX4 downstream of TGF- $\beta$ might be viable anti-fibrotic approaches. Clinically, two agents, pirfenidone and tranilast, which inhibit TGF- $\beta$ and other growth factors (Edgley et al., 2012), have been available. Both pirfenidone and tranilast have been shown to reduce cardiac fibrosis in animal studies (Edgley et al., 2012). However, tranilast was disappointing in the PRESTO study for post-percutaneous transluminal coronary angioplasty restenosis prevention (Holmes et al., 2002). The use of pirfenidone and tranilast also have adverse effects such as liver dysfunction. Now research is being conducted to search for new compounds that could overcome these potential safety concerns. A new compound called FT011 displays improved activity and reduced toxicity compared to tranilast (Zammit et al., 2009), which needs to be investigated in clinical studies.

\section{Endothelin Inhibitors}

Endothelin is another important contributor of fibrotic process and bosentan, a dual endothelin receptor subtype A and B antagonist, prevents fibrosis of various organs in animal models (Clozel and Salloukh, 2005). Dual endothelin subtype A and $\mathrm{B}$ inhibitors bosentan and macitentan and the ETA inhibitor ambrisentan are approved in the U.S. for the treatment of pulmonary hypertension. An initial small study in human showed that additional administration of bosentan improved systemic and pulmonary hemodynamics in severe heart failure patients receiving conventional treatments including ACE inhibitors (Sütsch et al., 1998). However, most of subsequent clinical trials of endothelin receptor antagonists were negative or neutral (Anand et al., 2004; Prasad et al., 2006). The harmful effects of endothelin receptor antagonists were generally 
attributable to enhanced fluid retention, which could be alleviated by early diuretic therapy. However, in general, additional blockade of endothelin may not be beneficial in patients with heart failure or cardiac fibrosis receiving angiotensin inhibitors.

\section{$\beta$-Blockers}

$\beta$-blockers have been demonstrated to prevent cardiac fibrosis and improve survival in a rat model (Kobayashi et al., 2004). A meta-analysis showed that the $\beta$-blockers treatment for the patients with heart failure with preserved ejection fraction was associated with a lower risk of all-cause mortality (Liu et al., 2014). However, the mechanisms of $\beta$-blockers' benefit on mortality have not been precisely clarified and whether $\beta$ blockers attenuate cardiac fibrosis in human remains unknown.

\section{Selective Heart Rate-Reducing Treatment: Ivabradine}

Ivabradine is an oral medication that provides selective heart rate reduction by inhibiting the f-channel. A large trial SHIFT showed that over a median follow-up of 22.9 months, ivabradine significantly reduced cardiovascular death or hospital admission for worsening heart failure in patients with symptomatic heart failure with an LV ejection fraction $\leq 35 \%$, and in sinus rhythm with a heart rate of $\geq 70$ bpm (Swedberg et al., 2010). An echocardiographic sub-study of SHIFT further found that ivabradine improved both LV end-systolic and end-diastolic volume indexes compared with placebo from baseline to the 8-month follow-up (Tardif et al., 2011). Thus, ivabradine has been introduced in the treatment guidelines for chronic heart failure in patients (McMurray et al., 2012). However, evidence on whether ivabradine attenuates cardiac fibrosis in patients with heart failure is still lacking although ivabradine effectively reduced fibrosis and circulating angiotensin II and aldosterone levels in animal models (Busseuil et al., 2010). Ivabradine could also reduce fibrosis through its inhibitory effects on inflammatory responses and cardiac apoptosis (Becher et al., 2012).

\section{Loop Diuretics: Torsemide}

There are three loop diuretics utilized in heart failure patients: furosemide, torsemide, and bumetanide. López et al. reported that torasemide $(n=19)$, but not furosemide $(n=17)$, reduced circulating PICP and myocardial collagen in hypertensive patients with symptomatic heart failure (López et al., 2004). They then found that activation of the enzyme responsible for the cleavage of PICP, procollagen type I carboxy-terminal proteinase (PCP), was also decreased in 22 patients with chronic heart failure taking torasemide (López et al., 2007). They further reported the ability of torsemide to correct both lysyl oxidase overexpression and enhanced collagen cross-linking leading to normalization of LV chamber stiffness in patients with heart failure (López et al., 2009). This was supported by preclinical data showing torsemide's effect on RAAS inhibition including decreasing aldosterone secretion, inhibiting aldosterone receptor and Ang II effects (Buggey et al., 2015). However, in the TORAFIC study, a multi-center study of 155 hypertensive patients with chronic heart failure randomized to torsemide or furosemide, investigators did not find significant differences between the two groups in changes of PICP (Group, 2011). The TORAFIC study's patient population had less severe heart failure and lower baseline serum PICP compared to those in the studies by Lopez and colleagues, which possibly explains the divergent results among these studies. So, it is important to select patients who may benefit from torsemide treatment.

\section{Sildenafil}

Sildenafil inhibits cyclic GMP-specific phosphodiesterase type$5 \mathrm{~A}$ and it has been used to treat idiopathic pulmonary fibrosis. In the first proof-of-concept human study, 59 patients with isolated diabetic cardiomyopathy randomly treated 3 months with sildenafil showed improved LV contraction parameters and reduced TGF- $\beta$ and monocyte chemoattractant protein-1, when compared with controls (Giannetta et al., 2012). However, among patients with heart failure with preserved ejection fraction sildenafil for 24 weeks $(n=113)$, compared with placebo $(n=$ 103), did not improve exercise capacity or clinical status (Redfield et al., 2013). Notably, fibrosis parameters were not measured in these two studies. The discordant results indicate that the same treatment does not exert similar effects in various cardiovascular disease.

\section{Matrix Metalloproteinase (MMP) Inhibitors}

Cardiac fibrosis is associated with activation of MMPs. It has been shown that MMP inhibition attenuates cardiac fibrosis and LV remodeling in experimental models (Heymans et al., 2005; Matsusaka et al., 2006). However, the PREMIER study of an orally active MMP inhibitor, PG-116800, in 253 patients after M failed to prevent LV remodeling or improve clinical outcomes 90 days after MI (Hudson et al., 2006), although it should be noted that no fibrosis parameters were measured in this study.

\section{Relaxin}

Relaxin is an intriguing endogenous hormone that is a potent vasodilator with a number of pleiotropic effects. Relaxin inhibits fibrosis through various mechanisms including inhibiting TGF$\beta$ and Smad, regulating the balance between MMPs and tissue inhibitors of metalloproteinases, and inhibiting inflammatory response (Samuel et al., 2016). Relaxin has been shown to have anti-fibrotic effects in a range of experimental models of cardiovascular disease including MI (Samuel et al., 2011), fibrotic cardiomyopathy (Samuel et al., 2014), hypertension (Lekgabe et al., 2005), diabetes (Samuel et al., 2008), and atrial fibrillation (Henry et al., 2016). Furthermore, relaxin more effectively ameliorated cardiac fibrosis than enalapril in an experimental model of fibrotic cardiomyopathy and relaxin in combination with enalapril augmented the anti-fibrotic efficacy of enalapril (Samuel et al., 2014). However, relaxin is not universally beneficial in cardiac fibrosis since relaxin did not affect pressure overload-induced cardiac fibrosis that was associated with biochemical wall stress rather than elevated TGF$\beta 1$ levels (Xu et al., 2008). The beneficial effects of a single 48-h infusion of relaxin in the acute heart failure trials (Teerlink et al., 2009, 2013) has led to great interest in its clinical application in in human disease. Although anti-fibrotic effects of relaxin 
is well characterized in various experimental models, clinical trials have failed in patients with other fibrotic conditions such as scleroderma (Khanna et al., 2009). The negative results of clinical trials of relaxin have pointed to the challenges previously underscored. First, relaxin has short in vivo half-life and it is costly to produce. The relatively short duration of relaxin treatment have partly contributed to the failed clinical trials since fibrosis is a slow process in human. Second, it is important to know the expression of relaxin receptors in different tissues and organs and to understand tissue competence to respond to relaxin along with signaling pathways. Nevertheless, relaxin still holds great potential as a therapy for cardiac fibrosis associated with various cardiovascular disease.

\section{CHALLENGES AND FUTURE DIRECTIONS}

The failure of many clinical trials on anti-fibrotic drugs indicates that extrapolating research data from animal models to human requires caution since there are significant species differences in physiology and genetics between animals and human. Compared to mice, fibrosis is a slower condition in humans, which takes decades to develop and require longterm treatment to diminish its progression. Furthermore, many animal models of diseases do not mimic various clinical settings, thus controversial results are likely to be obtained since there are different signaling pathways and mechanisms in cardiac fibrotic processes in various diseases. In addition, the animals used are normally young while patients with cardiac fibrosis are at a more advanced age. In order to improve clinical translation, it is important to design, conduct and analyse animal experiments properly and to summarize data from animal research adequately before conducting clinical trials. Moreover, the failure of previous trials also emphasizes the need for optimal design of future clinical trials including a selection of suitable patients, appropriate dose, and route and timing and length of administration.

There are some important areas for future research in this field. First, although CMR is too expensive to be used in large populations, it should be used to investigate potential

\section{REFERENCES}

Abulhul, E., McDonald, K., Martos, R., Phelan, D., Spiers, J. P., Hennessy, M., et al. (2012). Long-term statin therapy in patients with systolic heart failure and normal cholesterol: effects on elevated serum markers of collagen turnover, inflammation, and B-type natriuretic peptide. Clin. Ther. 34, 91-100. doi: 10.1016/j.clinthera.2011.11.002

Anand, I., McMurray, J., Cohn, J. N., Konstam, M. A., Notter, T., Quitzau, K., et al. (2004). Long-term effects of darusentan on left-ventricular remodelling and clinical outcomes in the EndothelinA Receptor Antagonist Trial in Heart Failure (EARTH): randomised, double-blind, placebo-controlled trial. Lancet 364, 347-354. doi: 10.1016/S0140-6736(04)16723-8

Ashton, E., Windebank, E., Skiba, M., Reid, C., Schneider, H., Rosenfeldt, F., et al. (2011). Why did high-dose rosuvastatin not improve cardiac remodeling in chronic heart failure? Mechanistic insights from the UNIVERSE study. Int. J. Cardiol. 146, 404-407. doi: 10.1016/j.ijcard.2009.12.028

Becher, P. M., Lindner, D., Miteva, K., Savvatis, K., Zietsch, C., Schmack, B., et al. (2012). Role of heart rate reduction in the prevention of experimental heart new treatments with relatively small group sizes since it allows accurate assessment of regional and diffuse fibrosis. Second, anti-fibrotic therapies targeting downstream signaling pathways may improve safety and efficacy of current treatments such as TGF- $\beta$ inhibitors. In addition to their role in fibrosis, many proteins are involved in other biological processes. Thus, developing more specific agents targeting fibrotic signaling pathways is likely to be beneficial to minimize potential side effects. Third, combined anti-fibrotic therapies seem more effective than single drug treatment. It is shown that spironolactone or relaxin in combination with angiotensin II inhibitors augmented anti-fibrotic efficacy (Kosmala et al., 2011; Samuel et al., 2014). Combined anti-fibrotic agents with different mechanisms of actions is likely to exert better effects on cardiac fibrosis.

\section{CONCLUSION}

Although many fibrotic therapies on cardiac fibrosis are promising in preclinical models, clinical translation is limited. There is still a lack of effective treatments to regress cardiac fibrosis in patients with various cardiovascular disease. Future optimally designed clinical studies are required to test new potential treatments and currently available drugs with improved safety and efficacy after adequate analysis of evidence from animal research.

\section{AUTHOR CONTRIBUTIONS}

LF was responsible for assembling and drafting of the manuscript. $\mathrm{AM}$ and $\mathrm{AD}$ contributed to the drafting of the manuscript.

\section{ACKNOWLEDGMENTS}

This study was supported in part by the Victorian Government's Operational Infrastructure Support Program. AD is an NHMRC fellow. AM is an NHMRC Career Development Fellow and a National Heart Foundation Future Leader Fellow. failure: comparison between If-channel blockade and beta-receptor blockade. Hypertension 59, 949-957. doi: 10.1161/HYPERTENSIONAHA.111.183913

Brilla, C. G., Funck, R. C., and Rupp, H. (2000). Lisinopril-mediated regression of myocardial fibrosis in patients with hypertensive heart disease. Circulation 102, 1388-1393. doi: 10.1161/01.CIR.102.12.1388

Buggey, J., Mentz, R. J., Pitt, B., Eisenstein, E. L., Anstrom, K. J., Velazquez, E. J., et al. (2015). A reappraisal of loop diuretic choice in heart failure patients. Am. Heart J. 169, 323-333. doi: 10.1016/j.ahj.2014.12.009

Busseuil, D., Shi, Y., Mecteau, M., Brand, G., Gillis, M. A., Thorin, E., et al. (2010). Heart rate reduction by ivabradine reduces diastolic dysfunction and cardiac fibrosis. Cardiology 117, 234-242. doi: 10.1159/000322905

Chang, S. A., Kim, Y. J., Lee, H. W., Kim, D. H., Kim, H. K., Chang, H. J., et al. (2009). Effect of rosuvastatin on cardiac remodeling, function, and progression to heart failure in hypertensive heart with established left ventricular hypertrophy. Hypertension 54, 591-597. doi: 10.1161/HYPERTENSIONAHA.109.131243

Chung, E. S., Packer, M., Lo, K. H., Fasanmade, A. A., Willerson, J. T., and Anti-TNF Therapy Against Congestive Heart Failure Investigators. (2003). 
Randomized, double-blind, placebo-controlled, pilot trial of infliximab, a chimeric monoclonal antibody to tumor necrosis factor-alpha, in patients with moderate-to-severe heart failure: results of the anti-TNF Therapy Against Congestive Heart Failure (ATTACH) trial. Circulation 107, 3133-3140. doi: 10.1161/01.CIR.0000077913.60364.D2

Clozel, M., and Salloukh, H. (2005). Role of endothelin in fibrosis and anti-fibrotic potential of bosentan. Ann. Med. 37, 2-12. doi: 10.1080/07853890410018925

Deswal, A., Richardson, P., Bozkurt, B., and Mann, D. L. (2011). Results of the Randomized Aldosterone Antagonism in Heart Failure with Preserved Ejection Fraction trial (RAAM-PEF). J. Card. Fail. 17, 634-642. doi: 10.1016/j.cardfail.2011.04.007

Díez, J., Querejeta, R., López, B., González, A., Larman, M., and Martínez Ubago, J. L. (2002). Losartan-dependent regression of myocardial fibrosis is associated with reduction of left ventricular chamber stiffness in hypertensive patients. Circulation 105, 2512-2517. doi: 10.1161/01.CIR.0000017264.66561.3D

Edgley, A. J., Krum, H., and Kelly, D. J. (2012). Targeting fibrosis for the treatment of heart failure: a role for transforming growth factor-beta. Cardiovasc. Ther. 30, e30-e40. doi: 10.1111/j.1755-5922.2010.00228.x

Engebretsen, K. V., Skårdal, K., Bjørnstad, S., Marstein, H. S., Skrbic, B., Sjaastad, I., et al. (2014). Attenuated development of cardiac fibrosis in left ventricular pressure overload by SM16, an orally active inhibitor of ALK5. J. Mol. Cell. Cardiol. 76, 148-157. doi: 10.1016/j.yjmcc.2014.08.008

Fang, L., Beale, A., Ellims, A. H., Moore, X. L., Ling, L. H., Taylor, A. J., et al. (2013). Associations between fibrocytes and postcontrast myocardial T1 times in hypertrophic cardiomyopathy. J. Am. Heart Assoc. 2:e000270. doi: 10.1161/JAHA.113.000270

Fang, L., Ellims, A. H., Moore, X. L., White, D. A., Taylor, A. J., Chin-Dusting, J., et al. (2015). Circulating microRNAs as biomarkers for diffuse myocardial fibrosis in patients with hypertrophic cardiomyopathy. J. Transl. Med. 13:314. doi: 10.1186/s12967-015-0672-0

Frantz, S., Hu, K., Adamek, A., Wolf, J., Sallam, A., Maier, S. K., et al. (2008). Transforming growth factor beta inhibition increases mortality and left ventricular dilatation after myocardial infarction. Basic Res. Cardiol. 103, 485-492. doi: 10.1007/s00395-008-0739-7

Giannetta, E., Isidori, A. M., Galea, N., Carbone, I., Mandosi, E., Vizza, C. D., et al. (2012). Chronic Inhibition of cGMP phosphodiesterase 5A improves diabetic cardiomyopathy: a randomized, controlled clinical trial using magnetic resonance imaging with myocardial tagging. Circulation 125, 2323-2333. doi: 10.1161/CIRCULATIONAHA.111.063412

Group, T. I. (2011). Effects of prolonged-release torasemide versus furosemide on myocardial fibrosis in hypertensive patients with chronic heart failure: a randomized, blinded-end point, active-controlled study. Clin. Ther. 33, 1204-1213.e1203. doi: 10.1016/j.clinthera.2011.08.006

Hamid, T., Gu, Y., Ortines, R. V., Bhattacharya, C., Wang, G., Xuan, Y. T., et al. (2009). Divergent tumor necrosis factor receptor-related remodeling responses in heart failure: role of nuclear factor- $\mathrm{\kappa B}$ and inflammatory activation. Circulation 119, 1386-1397. doi: 10.1161/CIRCULATIONAHA.108.802918

Henry, B. L., Gabris, B., Li, Q., Martin, B., Giannini, M., Parikh, A., et al. (2016). Relaxin suppresses atrial fibrillation in aged rats by reversing fibrosis and upregulating $\mathrm{Na}^{+}$channels. Heart Rhythm 13, 983-991. doi: 10.1016/j.hrthm.2015.12.030

Heymans, S., Gonzalez, A., Pizard, A., Papageorgiou, A. P., Lopez-Andres, N., Jaisser, F., et al. (2015). Searching for new mechanisms of myocardial fibrosis with diagnostic and/or therapeutic potential. Eur. J. Heart Fail. 17, 764-771. doi: 10.1002/ejhf.312

Heymans, S., Lupu, F., Terclavers, S., Vanwetswinkel, B., Herbert, J. M., Baker, A., et al. (2005). Loss or inhibition of uPA or MMP-9 attenuates LV remodeling and dysfunction after acute pressure overload in mice. Am. J. Pathol. 166, 15-25. doi: 10.1016/S0002-9440(10)62228-6

Holmes, D. R. Jr., Savage, M., LaBlanche, J. M., Grip, L., Serruys, P. W., Fitzgerald, P., et al. (2002). Results of Prevention of REStenosis with Tranilast and its Outcomes (PRESTO) trial. Circulation 106, 1243-1250. doi: 10.1161/01.CIR.0000028335.31300.DA

Hudson, M. P., Armstrong, P. W., Ruzyllo, W., Brum, J., Cusmano, L., Krzeski, P., et al. (2006). Effects of selective matrix metalloproteinase inhibitor (PG$116800)$ to prevent ventricular remodeling after myocardial infarction: results of the PREMIER (Prevention of Myocardial Infarction Early Remodeling) trial. J. Am. Coll. Cardiol. 48, 15-20. doi: 10.1016/j.jacc.2006.02.055
Kawamura, M., Ito, H., Onuki, T., Miyoshi, F., Watanabe, N., Asano, T., et al. (2010). Candesartan decreases type III procollagen-N-peptide levels and inflammatory marker levels and maintains sinus rhythm in patients with atrial fibrillation. J. Cardiovasc. Pharmacol. 55, 511-517. doi: $10.1097 /$ fjc.0b013e3181d70690

Khanna, D., Clements, P. J., Furst, D. E., Korn, J. H., Ellman, M., Rothfield, N., et al. (2009). Recombinant human relaxin in the treatment of systemic sclerosis with diffuse cutaneous involvement: a randomized, double-blind, placebocontrolled trial. Arthritis Rheum. 60, 1102-1111. doi: 10.1002/art.24380

Kjekshus, J., Apetrei, E., Barrios, V., Böhm, M., Cleland, J. G., Cornel, J. H., et al. (2007). Rosuvastatin in older patients with systolic heart failure. N. Engl. J. Med. 357, 2248-2261. doi: 10.1056/NEJMoa0706201

Kobayashi, M., Machida, N., Mitsuishi, M., and Yamane, Y. (2004). $\mu$-blocker improves survival, left ventricular function, and myocardial remodeling in hypertensive rats with diastolic heart failure. Am. J. Hypertens. 17(12 Pt 1), 1112-1119. doi: 10.1016/j.amjhyper.2004.07.007

Kong, P., Christia, P., and Frangogiannis, N. G. (2014). The pathogenesis of cardiac fibrosis. Cell. Mol. Life Sci. 71, 549-574. doi: 10.1007/s00018-013-1349-6

Kosmala, W., Przewlocka-Kosmala, M., Szczepanik-Osadnik, H., Mysiak, A., and Marwick, T. H. (2013). Fibrosis and cardiac function in obesity: a randomised controlled trial of aldosterone blockade. Heart 99, 320-326. doi: 10.1136/heartjnl-2012-303329

Kosmala, W., Przewlocka-Kosmala, M., Szczepanik-Osadnik, H., Mysiak, A., O'Moore-Sullivan, T., and Marwick, T. H. (2011). A randomized study of the beneficial effects of aldosterone antagonism on LV function, structure, and fibrosis markers in metabolic syndrome. JACC Cardiovasc. Imaging 4, 1239-1249. doi: 10.1016/j.jcmg.2011.08.014

Krum, H., Ashton, E., Reid, C., Kalff, V., Rogers, J., Amarena, J., et al. (2007). Double-blind, randomized, placebo-controlled study of high-dose HMG CoA reductase inhibitor therapy on ventricular remodeling, pro-inflammatory cytokines and neurohormonal parameters in patients with chronic systolic heart failure. J. Card. Fail. 13, 1-7. doi: 10.1016/j.cardfail.2006.09.008

Lekgabe, E. D., Kiriazis, H., Zhao, C., Xu, Q., Moore, X. L., Su, Y., et al. (2005). Relaxin reverses cardiac and renal fibrosis in spontaneously hypertensive rats. Hypertension 46, 412-418. doi: 10.1161/01.HYP.0000171930.00697.2f

Liu, F., Chen, Y., Feng, X., Teng, Z., Yuan, Y., and Bin, J. (2014). Effects of betablockers on heart failure with preserved ejection fraction: a meta-analysis. PLoS ONE 9:e90555. doi: 10.1371/journal.pone.0090555

López, B., González, A., Beaumont, J., Querejeta, R., Larman, M., and Díez, J. (2007). Identification of a potential cardiac antifibrotic mechanism of torasemide in patients with chronic heart failure. J. Am. Coll. Cardiol. 50, 859-867. doi: 10.1016/j.jacc.2007.04.080

López, B., Querejeta, R., González, A., Beaumont, J., Larman, M., and Díez, J. (2009). Impact of treatment on myocardial lysyl oxidase expression and collagen cross-linking in patients with heart failure. Hypertension 53, 236-242. doi: 10.1161/HYPERTENSIONAHA.108.125278

López, B., Querejeta, R., González, A., Sánchez, E., Larman, M., and Díez, J. (2004). Effects of loop diuretics on myocardial fibrosis and collagen type I turnover in chronic heart failure. J. Am. Coll. Cardiol. 43, 2028-2035. doi: 10.1016/j.jacc.2003.12.052

López, B., Querejeta, R., Varo, N., González, A., Larman, M., Martínez Ubago, J. L., et al. (2001). Usefulness of serum carboxy-terminal propeptide of procollagen type I in assessment of the cardioreparative ability of antihypertensive treatment in hypertensive patients. Circulation 104, 286-291. doi: 10.1161/01.CIR.104.3.286

Mak, G. J., Ledwidge, M. T., Watson, C. J., Phelan, D. M., Dawkins, I. R., Murphy, N. F., et al. (2009). Natural history of markers of collagen turnover in patients with early diastolic dysfunction and impact of eplerenone. J. Am. Coll. Cardiol. 54, 1674-1682. doi: 10.1016/j.jacc.2009.08.021

Mann, D. L., McMurray, J. J., Packer, M., Swedberg, K., Borer, J. S., Colucci, W. S., et al. (2004). Targeted anticytokine therapy in patients with chronic heart failure: results of the Randomized Etanercept Worldwide Evaluation (RENEWAL). Circulation 109, 1594-1602. doi: 10.1161/01.CIR.0000124490.27666.B2

Matsusaka, H., Ide, T., Matsushima, S., Ikeuchi, M., Kubota, T., Sunagawa, K., et al. (2006). Targeted deletion of matrix metalloproteinase 2 ameliorates myocardial remodeling in mice with chronic pressure overload. Hypertension 47, 711-717. doi: 10.1161/01.HYP.0000208840.30778.00 
McMurray, J. J., Adamopoulos, S., Anker, S. D., Auricchio, A., Böhm, M., Dickstein, K., et al. (2012). ESC Guidelines for the diagnosis and treatment of acute and chronic heart failure 2012: The Task Force for the Diagnosis and Treatment of Acute and Chronic Heart Failure 2012 of the European Society of Cardiology. Developed in collaboration with the Heart Failure Association (HFA) of the ESC. Eur. Heart J. 33, 1787-1847. doi: 10.1093/eurheartj/ehs104

Ogata, T., Miyauchi, T., Sakai, S., Takanashi, M., Irukayama-Tomobe, Y., and Yamaguchi, I. (2004). Myocardial fibrosis and diastolic dysfunction in deoxycorticosterone acetate-salt hypertensive rats is ameliorated by the peroxisome proliferator-activated receptor-alpha activator fenofibrate, partly by suppressing inflammatory responses associated with the nuclear factor-kappa-B pathway. J. Am. Coll. Cardiol. 43, 1481-1488. doi: 10.1016/j.jacc.2003.11.043

Prasad, S. K., Dargie, H. J., Smith, G. C., Barlow, M. M., Grothues, F., Groenning, B. A., et al. (2006). Comparison of the dual receptor endothelin antagonist enrasentan with enalapril in asymptomatic left ventricular systolic dysfunction: a cardiovascular magnetic resonance study. Heart 92, 798-803. doi: 10.1136/hrt.2004.049734

Querejeta, R., López, B., González, A., Sánchez, E., Larman, M., Martínez Ubago, J. L., et al. (2004). Increased collagen type I synthesis in patients with heart failure of hypertensive origin: relation to myocardial fibrosis. Circulation 110, 1263-1268. doi: 10.1161/01.CIR.0000140973.60992.9A

Redfield, M. M., Chen, H. H., Borlaug, B. A., Semigran, M. J., Lee, K. L., Lewis, G., et al. (2013). Effect of phosphodiesterase-5 inhibition on exercise capacity and clinical status in heart failure with preserved ejection fraction: a randomized clinical trial. JAMA 309, 1268-1277. doi: 10.1001/jama.2013.2024

Samuel, C. S., Bodaragama, H., Chew, J. Y., Widdop, R. E., Royce, S. G., and Hewitson, T. D. (2014). Serelaxin is a more efficacious antifibrotic than enalapril in an experimental model of heart disease. Hypertension 64, 315-322. doi: 10.1161/HYPERTENSIONAHA.114.03594

Samuel, C. S., Cendrawan, S., Gao, X. M., Ming, Z., Zhao, C., Kiriazis, H., et al. (2011). Relaxin remodels fibrotic healing following myocardial infarction. Lab. Invest. 91, 675-690. doi: 10.1038/labinvest.2010.198

Samuel, C. S., Hewitson, T. D., Zhang, Y., and Kelly, D. J. (2008). Relaxin ameliorates fibrosis in experimental diabetic cardiomyopathy. Endocrinology 149, 3286-3293. doi: 10.1210/en.2008-0250

Samuel, C. S., Royce, S. G., Hewitson, T. D., Denton, K. M., Cooney, T. E., and Bennett, R. G. (2016). Anti-fibrotic actions of relaxin. Br. J. Pharmacol. doi: $10.1111 / \mathrm{bph} .13529$. [Epub ahead of print].

Sarma, S. (2012). Use of clinically available PPAR agonists for heart failure; do the risks outweigh the potential benefits? Curr. Mol. Pharmacol. 5, 255-263. doi: 10.2174/1874467211205020255

Shibasaki, Y., Nishiue, T., Masaki, H., Tamura, K., Matsumoto, N., Mori, Y., et al. (2005). Impact of the angiotensin II receptor antagonist, losartan, on myocardial fibrosis in patients with end-stage renal disease: assessment by ultrasonic integrated backscatter and biochemical markers. Hypertens. Res. 28, 787-795. doi: 10.1291/hypres.28.787

Shimada, Y. J., Passeri, J. J., Baggish, A. L., O’Callaghan, C., Lowry, P. A., Yannekis, G., et al. (2013). Effects of losartan on left ventricular hypertrophy and fibrosis in patients with nonobstructive hypertrophic cardiomyopathy. JACC Heart Fail. 1, 480-487. doi: 10.1016/j.jchf.2013.09.001
Sütsch, G., Kiowski, W., Yan, X. W., Hunziker, P., Christen, S., Strobel, W., et al. (1998). Short-term oral endothelin-receptor antagonist therapy in conventionally treated patients with symptomatic severe chronic heart failure. Circulation 98, 2262-2268. doi: 10.1161/01.CIR.98.21.2262

Swedberg, K., Komajda, M., Böhm, M., Borer, J. S., Ford, I., DubostBrama, A., et al. (2010). Ivabradine and outcomes in chronic heart failure (SHIFT): a randomised placebo-controlled study. Lancet 376, 875-885. doi: 10.1016/S0140-6736(10)61198-1

Tardif, J. C., O’Meara, E., Komajda, M., Böhm, M., Borer, J. S., Ford, I., et al. (2011). Effects of selective heart rate reduction with ivabradine on left ventricular remodelling and function: results from the SHIFT echocardiography substudy. Eur. Heart J. 32, 2507-2515. doi: 10.1093/eurheartj/ehr311

Tavazzi, L., Maggioni, A. P., Marchioli, R., Barlera, S., Franzosi, M. G., Latini, R., et al. (2008). Effect of rosuvastatin in patients with chronic heart failure (the GISSI-HF trial): a randomised, double-blind, placebocontrolled trial. Lancet 372, 1231-1239. doi: 10.1016/S0140-6736(08) 61240-4

Teerlink, J. R., Cotter, G., Davison, B. A., Felker, G. M., Filippatos, G., Greenberg, B. H., et al. (2013). Serelaxin, recombinant human relaxin-2, for treatment of acute heart failure (RELAX-AHF): a randomised, placebo-controlled trial. Lancet 381, 29-39. doi: 10.1016/S0140-6736(12) 61855-8

Teerlink, J. R., Metra, M., Felker, G. M., Ponikowski, P., Voors, A. A., Weatherley, B. D., et al. (2009). Relaxin for the treatment of patients with acute heart failure (Pre-RELAX-AHF): a multicentre, randomised, placebo-controlled, parallel-group, dose-finding phase IIb study. Lancet 373, 1429-1439. doi: 10.1016/S0140-6736(09)60622-X

Westermann, D., Rutschow, S., Van Linthout, S., Linderer, A., Bücker-Gärtner, C., Sobirey, M., et al. (2006). Inhibition of p38 mitogen-activated protein kinase attenuates left ventricular dysfunction by mediating pro-inflammatory cardiac cytokine levels in a mouse model of diabetes mellitus. Diabetologia 49, 2507-2513. doi: 10.1007/s00125-006-0385-2

Xu, Q., Lekgabe, E. D., Gao, X. M., Ming, Z., Tregear, G. W., Dart, A. M., et al. (2008). Endogenous relaxin does not affect chronic pressure overloadinduced cardiac hypertrophy and fibrosis. Endocrinology 149, 476-482. doi: 10.1210/en.2007-1220

Zammit, S. C., Cox, A. J., Gow, R. M., Zhang, Y., Gilbert, R. E., Krum, H., et al. (2009). Evaluation and optimization of antifibrotic activity of cinnamoyl anthranilates. Bioorg. Med. Chem. Lett. 19, 7003-7006. doi: 10.1016/j.bmcl.2009.09.120

Conflict of Interest Statement: The authors declare that the research was conducted in the absence of any commercial or financial relationships that could be construed as a potential conflict of interest.

Copyright (C) 2017 Fang, Murphy and Dart. This is an open-access article distributed under the terms of the Creative Commons Attribution License (CC BY). The use, distribution or reproduction in other forums is permitted, provided the original author(s) or licensor are credited and that the original publication in this journal is cited, in accordance with accepted academic practice. No use, distribution or reproduction is permitted which does not comply with these terms. 